\title{
RAČUNOVODSTVENI INFORMACIONI SISTEM KAO PODRŠKA SAVREMENIM POSLOVNIM FINANSIJAMA
}

\author{
Edin Glogić1, Mirna Pajević ${ }^{2}$ \\ ${ }^{1}$ Fakultet poslovne ekonomije, Sveučilište/Univerzitet VITEZ, Travnik, Bosna i Hercegovina \\ ${ }^{2}$ Ekonomski fakultet, Univerzitet u Sarajevu, Sarajevo, Bosna i Hercegovina
}

\section{Apstrakt:}

Cilj ovog rada je da čitaocu i svim ostalim korisnicima prezentuje rezultate primjene savremenih tehnologija, odnosno računovodstvenih informacionih sistema u poslovnim finansijama. $U$ radu se želi prikazati način podrške računovodstvenih informacionih sistema savremenim poslovnim finansijama, odnosno različita područja njihove primjene u svakodnevnom poslovanju.

Istraživanjem smo utvrdili kako računovodstveni informacioni sistem utiče na unapređenje kvalitete poslovanja, kroz segment poslovnih finansija, što za rezultat ima rast i razvoj preduzeća, kao i podizanje nivoa inovativnosti u poslovnim procesima.

Rezultati istraživanja pokazuju da računovodstveni informacioni sistem djeluje na unapređenje funkcije poslovnih finansija, što posljedično dovodi do povećanja poslovnih performansi kao uslova za stvaranje konkurentske prednosti u turbulentnim uslovima poslovanja.
\end{abstract}

\section{UVOD}

Brojne su definicije o tome šta je informacija i koja je njena uloga. Termin informacija moguće je definisiti na više načina zavisno u kojem kontekstu, odnosno u kojoj situaciji koristimo istu. U našem slučaju informaciju možemo definisati kao moćan i neophodan poslovni resurs bez kojeg preduzeće nije u mogućnosti ostvariti poslovni rast i razvoj. Uspješno i kvalitetno upravljati preduzećem je nezamislivo bez adekvatnih informacija, posebno u vremenu kada su informacione tehnologije doživjele svoju ekspanziju i kada je komunikacija kao savremen alat razmjene informacija veoma razvijena. Da bi uspješno upravljali i vodili preduzeće neophodne su različite informacije kao što su: informacije iz domena finansija i računovodstva, kvantitativne i kvalitativne informacije, tehničko - tehnološke i mnoge druge poslovne i neposlovne informacije.

Kako bismo se detaljnije bavili istražavnjem informacije i njene uloge u savremenom poslovanju preduzeća, potrebno je primjetiti da se informacije: prikupljaju, obrađuju, klasifikuju i čuvaju unutar preduzeća. Da bi bilo moguće operisati sa informacijama potrebno je imati integrisan skup komponenti za obradu informacija, a takav skup integrisanih komponenti možemo definisati kao informacioni sistem [1]. Jedan informacioni sistem čini više različitih podsistema. Informacije koje se koriste u preduzeću prilikom donošenja poslovnih odluka prikupljaju se iz mnogobrojnih izvora. Značajna uloga u prikupljanju, obradi i pripremanju poslovnih informacija za donošenje kvalitetnih odluka svakako pripada računovodstvenom informacionom sistemu [2].

Računovodstveni informacioni sistem je sam za sebe funkcionalan sistem, ali je u isto vrijeme i važan podsistem ukupnog informacionog sistema. Najveći broj poslovnih informacija koje koristimo u svakodnevnom poslovanju preduzeća i donošenju kvalitetnih poslovnih odluka dolazi upravo iz računovodstvenog informacionog sistema. Ako posmatramo sve podsisteme unutar jednog informacionog sistema preduzeća moguće je napraviti njihovu klasifikaciju prema vrsti finalnih informacija, pa tako za računovodstveni informacioni sistem možemo reći da je sistem koji je usmjeren na obradu i proizvodnju kvalitetnih kvantitativnih finansijskih informacija. Unutar računovodstvenog informacionog sistema primarno će biti zabilježene sve poslovne transakcije koje je moguće vrijednosno iskazati. Kod donošenja poslovnih odluka potrebno je uzeti sve raspoložive informacije u obzir. Kako bi bila doneta što ispravnija i kvalitetnija odluka možemo reći da informacije iz računovodstvenog informacionog sistema predstavljaju neizostavan dio poslovne strategije svakog uspješnog menadžmenta savremenog preduzeća.

\section{PRIMJENA RAČUNOVODSTVENOG INFORMACIONOG SISTEMA U POSLOVNIM FINANSIJAMA PREDUZEĆA}

Kada posmatramo preduzeće kao cjelinu možemo uočiti da unutar preduzeća postoje poslovne funkcije [3]. U zavisnosti od djelatnosti preduzeća poslovne funkcije se mogu razlikovati. Međutim, postoje funkcije u preduzeću koje možemo okarakterisati kao univerzalne, odnosno zajedničke za bilo koje preduzeće, a to su računovodstvena, finansijska, prodajna, funkcija upravljanja ljudskim resursima i ostale. Sve poslovne funkcije u preduzeću su važne, međutim finansijska funkcija bi trebala biti jedna od najvažnijih poslovnih funkcija unutar preduzeća. Bez obzira na značaj, finansijska funkcija nikada nije dobila primat nad ostalim funkcijama u preduzeću, već zajedno sa njima čini jednu sinergijsku cjelinu [4]. U vrijeme izražene nestašice novčanih sredstava i visoke cijene kapitala primarni zadatak koji se postavlja pred finansijsku funkciju u preduzeću, odnosno pred poslovne finansije preduzeća, je kako i na koji način kvalitetno upravljati novčanim sredstvima. Neusklađen rad poslovnih funkcija u preduzeću može da dovede do konflikta, a rezultat često može biti nestabilan cjelokupan poslovni sistem (preduzeće). Svako preduzeće bi u svom poslovanju trebalo da teži korišćenju savremene informacione tehnologije s ciljem optimizacije i unapređenju poslovnih procesa i funkcija. Savremeni 
računovodstveni informacioni sistem kao podrška poslovnim finansijama treba da pruži pouzdane finansijske informacije korisniku, odnosno menadžmentu preduzeća u svakom trenutku, kako bi menadžment na osnovu takvih informacija donosio kvalitetne poslovne odluke koje će za rezultat imati uspješno poslovanje preduzeća. Osnovni ciljevi poslovnih finansija, odnosno finansijskog upravljanja izraženi su u zahtjevima za maksimiziranjem rentabilnosti i profitabilnosti uz istovremeno održavanje odgovarajućeg stepena likvidnosti. Pored navedenih osnovnih ciljeva, interes menadžmenta poslovnih finansija je da osigura [5]:

- solventnost,

- sigurnost i stabilnost finansiranja,

- fleksibilnost finansiranja,

- upravljanje rizikom finansiranja,

- povoljnost finansijske situacije, te

- finansijsku nezavisnost.

Da bi preduzeće funkcionisalo i poslovalo uspješno, jedan od osnovnih zadataka iz domena poslovnih finansija je održavanje zadovoljavajućeg stepena likvidnosti, odnosno preduzeće treba biti sposobno da blagovremeno izvršava dospjele obaveze u odgovarajućim sredstvima plaćanja. Potrebno je da finansijski menadžment u preduzeću planski osigura brz obrt, odnosno nesmetanu cirkulaciju imovine (prije svega obrtnih sredstava). Ukoliko imamo spor obrt obrtne (kratkoročne) imovine, preduzeće je nelikvidno. Upravo zato, menadžement svakog preduzeća treba aktivno da koristi računovodstveni informacioni sistem u poslovnim finansijama, kao poslovni alat za finansijske analize, finansijska planiranja, i samim time za upravljanje poslovnim finansijama, odnosno za upravljanje novcem i novčanim ekvivalentima. Savremeni računovodstveni informacioni sistem finansijskom menadžmentu preduzeća, na zahtjev, treba da prezentuje informaciju o potraživanjima, obavezama, stanju tekuće imovine, informaciji o neusklađenosti ročnosti između aktive i pasive, i to:

- Visini i strukturi dospjelih potraživanja od kupaca - u ovom dijelu računovodstveni informacioni sistem korisniku mora da obezbijedi analitički rasčlanjenu informaciju o visini dospjelih potraživanja po svakom kupcu pojedinačno, ročnosti nedospjelih potraživanja sa prikazanim rokom dospijeća. Ako postoji kašnjenje u naplati potraživanja, onda bi sistem automatski trebalo da prikaže strukturu kašnjenja vremenski i finansijski,

- Obavezama prema dobavljačima - u ovom dijelu računovodstveni informacioni sistem mora minimalno da korisniku obezbijedi analitički rasčlanjenu informaciju o visini dospjelih obaveza po svakom dobavljaču pojedinačno, ročnosti nedospjelih obaveza sa prikazanim rokom dospijeća, ako postoji kašnjenje u plaćanju obaveza, onda bi sistem automatski trebao da prikaže strukturu kašnjenja vremenski i finansijski,

- Zalihama robe, materijala, proizvoda - kada je ovaj segment u pitanju računovodstveni informacioni sistem menadžmentu treba da ponudi informaciju o zalihama robe, materijala, proizvoda u smislu informacije o kretnju zaliha (prodaja, nabavka), informaciju o obrtu zaliha, starosnoj strukturi zaliha i na kraju o visini zaliha u momentu traženja informacije, jer vrlo često kada se nabavljaju zalihe na prodajnim akcijama po sniženim cijenama zanemari se visina trenutnih zaliha što rezultira gomilanjem istih, a to može biti jedan od razloga koji narušava i remeti likvidnost preduzeća,

- Uplaćeni avansi dobavljačima - računovodstveni informacioni sistem treba menadžmentu da (korisnicima sistema) prezentuje informaciju o sredstvima koja su uplaćena povjeriocima na ime avansa. Ova novčana sredstva su iskazana u aktivi preduzeća dok se ona fizički nalaze kod povjerioca i samim tim postoji rizik da bi $\mathrm{u}$ budućnosti moglo doći do narušavanja likvidnosti, jer preduzeće nema potpunu kontrolu nad tim novčanim sredstvima.

Finansijski menadžment u preduzeću koristeći računovodstveni informacioni sistem kao bazu za crpljenje evidentiranih finansijskih informacija iz prošlosti značajno unapređuje funkciju poslovnih finansija u preduzeću time što u svakom trenutku ima na raspolaganju kvalitetne i pouzdane informacije koje će koristiti za održavanje zadovoljavajućeg stepena likvidnosti preduzeća. Na osnovu informacija iz računovodstvenog informacionog sistema menadžment preduzeća je u mogućnosti provesti brzo i jednostavno razne finansijske analize, i na osnovu pokazatelja i raspoloživih informacija napraviti kvalitetno finansijsko planiranje (finansijski plan). Ovakve aktivnosti finansijskog menadžmenta u preduzeću koji koristi računovodstveni informacioni sistem imaju za rezultat renatabilno poslovanje i likvidno preduzeće, što je osnova njegovog rasta i razvoja u budućnosti.

\section{REZUTATI ISTRAŽIVANJA ZASTUPLJENOSTI KORIŠTENJA RAČUNOVODSTVENOG INFORMACIONOG SISTEMA U POSLOVANJU PREDUZEĆA U BIH}

Prilikom sprovođenja istraživanja putem anketnih upitnika, anketirano je ukupno 189 (100\%) ispitanika, od ukupnog broja anketiranih ispitanika na pitanje „Da li koriste neki oblik računovodstvenog informacionog sistema u svom poslovanju?" potvrdno je odgovorilo 100 ispitanika ili 53\%, dok je negativno odgovorilo 89 ispitanika ili $47 \%$.

\begin{tabular}{ccc}
\hline Ukupan broj ispitanika & 189 & $100 \%$ \\
\hline Broj ispitanika koji koriste RIS & 100 & $53 \%$ \\
\hline Broj ispitanika koji ne koriste RIS & 89 & $47 \%$ \\
\hline
\end{tabular}

Obrađujući dobijene rezultate dolazimo do određenih spoznaja, i to: od 53\% istraživanjem obuhvaćenih ispitanika, odnosno 100 ispitanika sa potvrdnim odgovorom da u svom poslovanju koriste neki oblik računovodstvenog informacionog sistema, 71\% ili sedamdeset jedan ispitanik se potpuno slaže da kompjuterizovani računovodstveni informacioni sistem unapređuje i olakšava poslovanje privrednog društva, dok se $23 \%$ ili dvadeset tri ispitanika djelomično slažu sa prethodnom konstatacijom, a $6 \%$ ili šest ispitanika se ne slaže da korištenje računovodstvenog informacionog sistema unapređuje i olakšava poslovanje preduzeća.

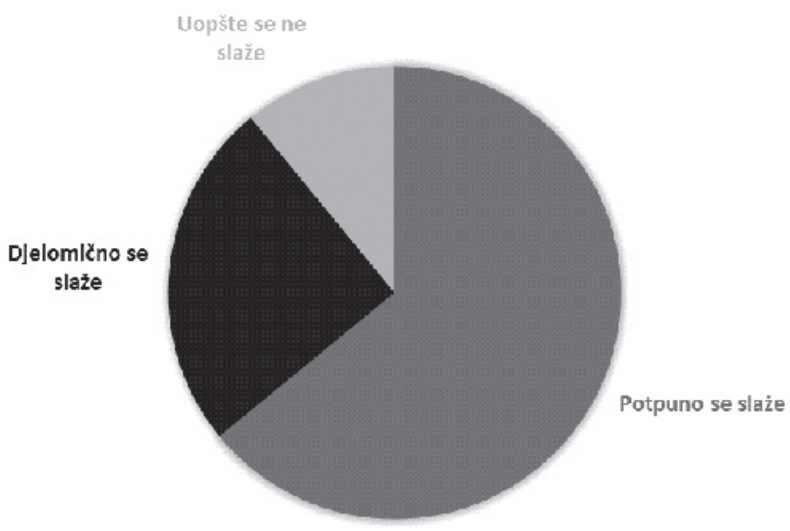

Grafikon 1. Prikaz mišljenja ispitanika o korištenju RIS-a 
Istraživanjem smo došli do spoznaja o upotrebi informacija iz savremenog računovodstvenog informacionog sistema prilikom donošenja poslovnih odluka. Tako, više od pola ispitanika koji su u istraživanju odgovorili da koriste računovodstveni informacioni sistem u poslovanju, odnosno (65\%) tvrdi da se kod donošenja poslovnih odluka ponekad oslanjaju na podatke iz RIS-a, dok se $24 \%$ ispitanika nikad ne oslanja na RIS, već poslovne odluke donosi isključivo na osnovu vlastite intuicije i zaključaka. Svega $11 \%$ ispitanika je odgovorilo da su poslovne odluke koje donosi u potpunosti zasnovane na informacijama iz računovodstvenog informacionog sistema koji koriste.

Zastupljenost RIS-a kod donošenja odluka

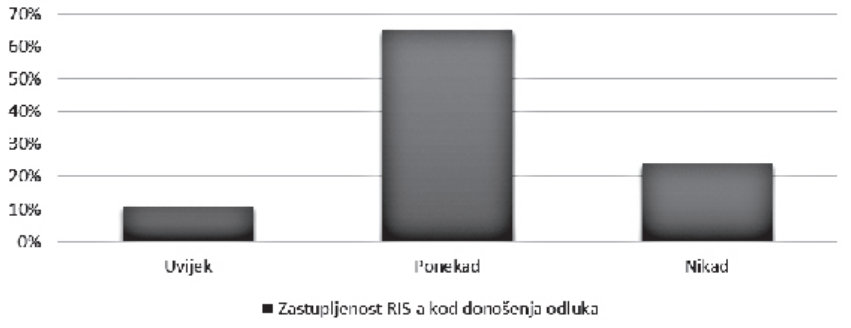

Grafikon 2. Prikaz zastupljenosti RIS-a kod donošenja poslovnih odluka

I pored ekspanzije i razvoja informacionih tehnologija još uvijek mali broj preduzeća u svom poslovanju koristi savremene informacione tehnologije. Istraživanje je pokazalo da je svega 53\% (100 ispitanika), od ukupnog broja ispitanika obuhvaćenih istraživanjem u $\mathrm{BiH}$, uvidjelo da korištenjem kompjuterizovanog računovodstvenog informacionog sistema značajno unapređuju i pospješuju poslovanje preduzeća, što posljedično dovodi do povećanja poslovnih performansi kao uslova za stvaranje konkurentske prednosti u turbulentnim uslovima poslovanja.

\section{ZAKLJUČAK}

Zaključak i preporuka ovog rada je da računovodstveni informacioni sistem predstavlja kvalitetnu podršku poslovnim finansijama. Podrška se ogleda u obezbeđenju i prezentaciji potrebnih i kvalitetnih poslovnih i finansijskih informacija za potrebe finansijskog menadžmenta u preduzeću, a sve u cilju donošenja pravih poslovnih odluka. Sprovodeći istraživanje došlo se do zaključka da veliki broj preduzeća u BiH još uvijek ne koristi savremene računovodstvene informacione sisteme u svom poslovanju. Menadžment u preduzećima u $\mathrm{BiH}$ nije dovoljno upoznat sa mogućnostima i benefitima primjene i korištenja savremenih informacionih tehnologija u poslovanju preduzeća, a samim time su uskraćeni za kvalitetne i pouzdane informacije koje bi značajno povećale kvalitet i brzinu donetih odluka. Ako posmatramo zemlje u okruženju, možemo primjetiti da je oblast računovodstvenih informacionih sistema i računovodstvenih software-a uređena i standardizovana, što u $\mathrm{BiH}$ nije slučaj. Mišljenja smo da je potrebno da nadležna profesionalna tijela za računovodstveno i finansije u $\mathrm{BiH}$ donesu i usvoje bar jedan dokument u obliku računovodstvenog standarda, zakona, uputstva ili neki drugi sličan akt kojim bi se regulisala oblast računovodstvenog software-a. Time bi se povećao kvalitet računovodstvenih informacionih sistema, a samim time i poboljšala podrška poslovnim finansijama, što u konačnici rezultira boljim poslovnim, a unutar njih i finansijskim performansama.

\section{LITERATURA}

[1] Kurtanović S., Glogić E., "Računovodstveni informacioni sistem kao faktor jačanja konkurentske sposobnosti preduzeća”, 1. Međunarodni simpozij Vlašić, Bosna i Hercegovina, 2013.

[2] Glogić E, "Računovodstveni informacioni sistem privrednih subjekata u FBiH”, Naučni magistarski rad, BiH, 2014, p.20

[3] Mamić S. I., Žager K., "Računovodstveni informacijski sustavi“, Hrvatska, Zagreb, 2008, p. 8

[4] Gligorić-Vujnović B., "Poslovne finansije”, Bosna i Hercegovina, Banja Luka, 2007, p. 3

[5] Gligorić-Vujnović B., "Poslovne finansije”, Bosna i Hercegovina, Banja Luka, 2007, p. 4

\title{
ACCOUNTING INFORMATION SYSTEM AS A SUPPORT FOR MODERN BUSINESS FINANCE
}

\author{
Edin Glogić1 Mirna Pajević \\ ${ }^{1}$ Faculty of Business Economics, University “VITEZ”, Kalesija Gornja br. 10, Kalesija, Bosnia and Herzegovina, edin.glogic@gmail.com \\ ${ }^{2}$ The School of Economics and Business in Sarajevo, University of Sarajevo, Sarajevo, Bosnia and Herzegovina, mirna_pajevic@hotmail.com
}

\section{Abstract}

The aim of this work is presenting the application of modern technology, and accounting information systems in business financing to the reader and all other users.

This work aims to show the ways of supporting accounting information systems to modern business financing, and various applications of it in daily business operations.

The study was intended to determine how accounting information systems affects the improvement of quality business, through the segment of business finances, that results to growth and development of enterprises, as well as raising the level of innovation in business processes. The results shows that accounting information systems operates on improving the functions of business finance, which consequently leads to increase business performance as a condition for the creation of competitive advantages in turbulent business environment.

\section{Key words:}

accounting, business finance, accounting information system. 